\title{
Repeated Application of Rice Straw Stabilizes Soil Bacterial Community Composition and Inhibits Clubroot Disease
}

\author{
Zhe Han, Chengqian Di, Muhammad Khashi u Rahman, Danmei Gao, Fengzhi Wu and Kai Pan * \\ Department of Horticulture and Landscape, Northeast Agricultural University, HarBin 150030, China; \\ hanzhe6615@aliyun.com (Z.H.); princedcq@sina.com (C.D.); khashiurahman@neau.edu.cn (M.K.uR.); \\ dmgao2019@neau.edu.cn (D.G.); fzwu2006@aliyun.com (F.W.) \\ * Correspondence: mugonglin@aliyun.com; Tel.: +86-451-55190563
}

check for updates

Citation: Han, Z.; Di, C.; Rahman, M.K.u; Gao, D.; Wu, F.; Pan, K.

Repeated Application of Rice Straw Stabilizes Soil Bacterial Community Composition and Inhibits Clubroot Disease. Agriculture 2021, 11, 108 https://doi.org/10.3390/agriculture 11020108

Academic Editors: Mohsin Tanveer, Mirza Hasanuzzaman, Ejaz Ahmad Khan and Massimo Cecchini Received: 10 December 2020

Accepted: 28 January 2021

Published: 31 January 2021

Publisher's Note: MDPI stays neutral with regard to jurisdictional claims in published maps and institutional affiliations.

Copyright: (c) 2021 by the authors. Licensee MDPI, Basel, Switzerland. This article is an open access article distributed under the terms and conditions of the Creative Commons Attribution (CC BY) license (https:/ / creativecommons.org/licenses/by/ $4.0 /)$.

\begin{abstract}
Straw amendment can improve soil properties and is an effective strategy to control soil-borne diseases. However, gramineous straw application to vegetable fields has rarely been studied. In this study, rice straw was added to the field of Chinese cabbage for one or two years (repeated), and Chinese cabbage plant growth, disease occurrence and changes in soil chemical properties were measured. In addition, the bacterial community composition of Chinese cabbage was analyzed using Illumina MiSeq sequencing. Results showed that rice straw application increased the content of available nutrients, $\mathrm{pH}$ and electrical conductivity, but decreased the diversity and richness of the bacterial community. The relative abundances of Acidobacteria and Chloroflexi were increased after repeated rice straw application, which were associated with the available potassium and $\mathrm{pH}$ in the soil. Network analysis revealed that rice straw amendment differentially affected the key bacterial genera. These results suggest that repeated application of rice straw changed the soil chemical properties and altered the bacterial community composition to suppress the clubroot disease incidence in Chinese cabbage.
\end{abstract}

Keywords: rice straw; Chinese cabbage; Plasmodiophora brassicae; clubroot; soil chemical properties; soil bacterial community

\section{Introduction}

Clubroot, caused by the obligate parasite Plasmodiophora brassicae, is a serious and prevailing soil-borne disease threatening global brassica production [1]. In China, approximately 3.2-4.0 ha of cruciferous crops is affected by clubroot annually, reducing crop yield or even causing total crop failure [2]. In disease control, chemical agents lead to soil deterioration, and resistant varieties are limited due to variation in physiological race [3]. Therefore, ecological methods seem especially important for preventing and controlling clubroot.

As a soil-borne disease, the amount of pathogen inoculation is closely related to disease occurrence. In clubroot, the higher rate of pathogen survival makes it difficult to control the disease because of the longevity of resting spores ( $>20$ years in soil) [4]. The growth of zoospores, which is closely related to moisture, leads to root hair infection [5]. Thereafter, secondary zoospores infect cortical cells and damages the root [6]. Studies have shown that non-host crops can stimulate spore germination, while bait crops can reduce pathogen proliferation, but the results thus far have not been satisfactory $[7,8]$. In addition to abiotic factors, the important role of the microbial community, such as plant growth-promoting rhizobium (PGPR), in disease suppression has been well-documented now $[9,10]$. In biological control measures, antagonistic bacteria, such as Bacillus and Streptomyces, is isolated from rhizosphere and endophytes of plants, which are considered as promising candidate agents against clubroot [11]. However, a limiting factor of their application depends on their instability effect, particularly in dynamic soil biogeochemical environment of the field $[12,13]$. Even so, the microbial community has great potential to control pathogen infection and improve crop production. 
Crop rotation is the simplest and most effective strategy for the management of plant diseases, including clubroot, but the practice is limited by economic value, operating means, and limited cropping options [14,15]. The rotation patterns of leguminous (soybean and clover) and gramineous (rice and maize) plants can alleviate the occurrence of clubroot [16] The actual experience of local farmers is that clubroot root symptoms can be relieved by the crop rotation with wheat or maize, which can also result in an increase in crop yield. Moreover, the plant straw represents the main physical and chemical compositions of plants, thus introduction of exogenous straw can potentially have similar effects as introduction of whole crop on soil physicochemical properties and microbial communities.

Straw amendment with a suitable tillage measure could play a critical role in regulating soil environment. Previously, it was shown that the abundance of pathogenic-antagonist microbial communities was positively related to straw decomposition rate [17]. However, the main focus of previous studies was the effect of crop residues on the same crop field. Here, we studied the effects of amendment of heterospecific crop straw (rice) on soil physicochemical properties and bacterial communities of Chinese cabbage. We hypothesized that the addition of rice straw could partially replace the Chinese cabbage continuous cropping effects, improve plant growth and control clubroot due to the improvement in soil environment.

\section{Materials and Methods}

\subsection{Study Area}

The area selected is located in Baicheng Village, Acheng District, Harbin, China $\left(126^{\circ} 59^{\prime} \mathrm{E}, 45^{\circ} 29^{\prime} \mathrm{N}\right)$, where a traditional double-cropping system-i.e., spring garlic (Allium sativum) and autumn Chinese cabbage (Brassica rapa pekinensis) - has been practiced for more than 30 years. The location has temperate continental monsoon climate, with annual precipitation of $542 \mathrm{~mm}$, and a mean annual temperature of $4{ }^{\circ} \mathrm{C}$. The incidence of clubroot of Chinese cabbage has been serious from last 10 years and cultivated fallow and resistant varieties have limited effects.

The soil was black soil (Mollisol) in the study area, and soil samples were collected to determine the chemical properties before sowing Chinese cabbage in July 2016. The soil contained $30.70 \mathrm{mg} \mathrm{kg}^{-1}$ of soil organic matter (SOM), $130.41 \mathrm{mg} \mathrm{kg}^{-1}$ of available nitrogen (AN), $125.25 \mathrm{mg} \mathrm{k}^{-1}$ of available phosphorus (AP), $622.50 \mathrm{mg} \mathrm{kg}^{-1}$ of available potassium (AK), 6.43 of $\mathrm{pH}$ and $0.398 \mathrm{mS} \mathrm{cm}^{-1}$ of electrolytic conductivity (EC). The basic soil chemical properties before sowing in July 2017 are listed in Supplementary Table S1.

For the Chinese cabbage cultivar, Gailiangdongbai 1 (susceptible to P. brassicae) provided by the Cabbage Research Group of Northeast Agricultural University (Harbin, China) was used [18]. Rice (Oryza sativa) straw was collected from a conventional rice production field in the suburban district of Harbin, then naturally air-dried in the shade and chopped into 3-5 cm pieces for further use. The straw was comprised of $62.58 \%$ organic matter, $0.76 \%$ total nitrogen, $0.52 \%$ total phosphorus, $3.20 \%$ total potassium and 82.74 carbon to nitrogen ratio $(\mathrm{C} / \mathrm{N})$.

\subsection{Experimental Design}

The study was conducted in July 2016, after the garlic harvest. Nine plots were selected in a randomized block design with three replicates. For the two-year application (SR; 3 plots), rice straw was added into the field after garlic harvest in both 2016 and 2017. For one-year application (FR; 3 plots), rice straw was added after garlic harvest only in 2017. For control (CK; 3 plots), no rice straw was added in 2016 or 2017 . Plot sizes of $3 \times 4 \mathrm{~m}$ per replicate were maintained, and $60 \times 60 \mathrm{~cm}$ plant spacing was used in plantation of Chinese cabbage. In straw-addition treatments, $3.5 \mathrm{~kg}$ of rice straw was applied $15 \mathrm{~cm}$ deep in the plots before sowing. In spring of both years, rotten cow dung $\left(30 \mathrm{~m}^{3} \mathrm{ha}^{-1}\right)$ was applied in the field. A compound fertilizer (N, 18\%; $\mathrm{P}_{2} \mathrm{O}_{5}, 46 \% ; 450 \mathrm{~kg} \mathrm{ha}^{-1}$ ) was used for fertilization twice a year before the plantation of both garlic and Chinese cabbage. The urea $\left(375 \mathrm{~kg} \mathrm{ha}^{-1}\right.$ ) was applied in late August of both years. Irrigation measures were used in the cultivation process according to the rainfall situation. 


\subsection{Measurement of the Plant Quality and Disease Incidence}

Fifty days after sowing, the fresh and dry plant weight were measured by the conventional weighing method. The disease index was measured 30 days after sowing using the following calculation method [19]:

Incidence rate $(\%)=$ Number of diseased plants/Total number of investigated plants $\times 100$

Disease index $=\left(\sum\right.$ (Number of diseased plants at each stage $\times$ Relative value $\left.)\right) /($ Total number of plants under investigation $\times$ Highest incidence of disease $) \times 100$

\subsection{Soil Sampling and Chemical Properties Analysis}

Soil samples were collected for a depth of $0-10 \mathrm{~cm}$ around the plant at four different periods (10, 20, 40 and 60 days after sowing), and three soil samples were mixed to make a soil sample for one replicate. The soil samples were transferred to the laboratory quickly in sealed plastic bags and then sieved using a $2 \mathrm{~mm}$ mesh to remove the visible impurities. The air-dried soil samples were used for the determination of the soil properties, and the partially fresh soil samples were stored at $-70^{\circ} \mathrm{C}$ in a refrigerator for microbiological determination.

The soil chemical properties were analyzed in the laboratory, $\mathrm{pH}$ and EC were determined using a glass electrode and a conductivity meter in a soil-water suspension (1:5, weight/volume) [20]. SOM was extracted using $\mathrm{K}_{2} \mathrm{Cr}_{2} \mathrm{O}_{7}$ and $\mathrm{H}_{2} \mathrm{SO}_{4}$ and titrated with $\mathrm{FeSO}_{4} \cdot 7 \mathrm{H}_{2} \mathrm{O}$ [21]. AN and AP in the soil were extracted with $2.0 \mathrm{M}$ of $\mathrm{KCl}$ and $0.5 \mathrm{M}$ of $\mathrm{NaHCO}_{3}$ respectively, and a continuous flow analyzer (San++, Skalar Analytical corporation, Breda, Netherlands) was used to analyze the soil filtrates [22]. AK was extracted with $1.0 \mathrm{M}$ of $\mathrm{NH}_{4} \mathrm{Ac}$ and quantified by inductively coupled plasma-atomic emission spectrometry (OCPS-7500, Shimadzu corporation, Kyoto, Japan) [21].

\subsection{DNA Extraction and Quantitative Polymerase Chain Reaction (PCR) Analysis}

The soil microbial DNA was extracted using a PowerSoil DNA Isolation Kit (Mo Bio Laboratories Inc., Carlsbad, CA, USA) according to the manufacturer's protocols. The abundance of $P$. brassicae in the soil was determined by SYBR Green quantitative PCR assays in an IQ5 real-time PCR system (Bio-Rad Lab, Hercules, CA, USA). Based on the internal transcribed spacer (ITS) region of P. brassicae, the Pb4-1/PbITS6 primers were used [23].

\subsection{Illumina MiSeq Sequencing and Data Processing}

Illumina MiSeq sequencing was used to analyze the total community composition of the soil [24]. The 16S rRNA genes in the V3-V4 region of the bacteria were analyzed using primers $341 \mathrm{~F}$ and $806 \mathrm{R}$, and two copies of each duplicate were used. Purified amplicons were pooled in equimolar and paired-end sequences (PE250) on an Illumina platform according to the standard protocols. The PCR amplicon products were extracted, purified, and quantified using the ABI StepOnePlus Real-Time PCR System (Applied Biosystems, Foster City, CA, USA) [22]. The raw reads were further filtered and merged under specific filtering conditions and searched against the reference database [25-29]. The effective tags were clustered into operational taxonomic units (OTUs) of $97 \%$ similarity using UPARSE [30]. The tag sequence with the highest abundance was selected as the representative sequence within each cluster. All raw sequences were deposited in the NCBI Sequence Read Archive with the submission Accession Number PRJNA694008.

\subsection{Statistical Analysis}

Quantitative data were analyzed by one-way analysis of variance, repeated-measures ANOVA (RMA), and Pearson's linear correlation analysis in SPSS software (Version 19.0, Armonk, NY, USA). Tukey's honestly significant difference (HSD) test was performed for the mean comparison. Figures were processed using OriginPro software (Version 8.5, OriginLab Corporporation, Northampton, MA, USA). The alpha diversity index was calculated in QIIME [27]. Beta diversity analysis of the principal coordinates analysis 
(PCoA) multivariate statistical technique based on the Jaccard distance was conducted using Vegan and ggplot2 packages in the R project.

The representative sequences were classified using the Ribosomal Database Project (RDP) classifier [31] based on the SILVA database [32] with a confidence threshold value of 0.8. The linear discriminant analysis (LDA) effect size (LEfSe) method ensured that the selection of abundant bacterial phyla and genera was significantly associated with the rice straw treatment. A network of the correlation coefficient was generated using igraph package in $\mathrm{R}$ project.

\section{Results and Discussion}

\subsection{The Plant Growth Responses to the Addition of Rice Straw}

For the analysis of plant weight, the fresh and dry weight were measured, with a distinction between the aboveground and belowground parts (Figure 1A,B). It was found that plant weight was significantly higher in FR than CK and SR $(p<0.05)$. In SR, the fresh weight of the aboveground parts was significantly higher than CK $(p<0.05)$. Crop straw addition is an important management practice, contributing to an increase in plant growth and crop yield [33]. In a previous study, maize and wheat residue application promoted the seedling growth of cucumber [34]. Crop yield and quality are largely affected by soil-borne pathogens which cause deterioration of the physical, chemical and biological qualities of the soil [35]. The incidence rate of clubroot decreased with straw treatment and was significantly lower in SR than in CK (Figure 1C) $(p<0.05)$. The amendment of rice residues had obvious effects on Chinese cabbage plant growth and development (Figure 1D-F).
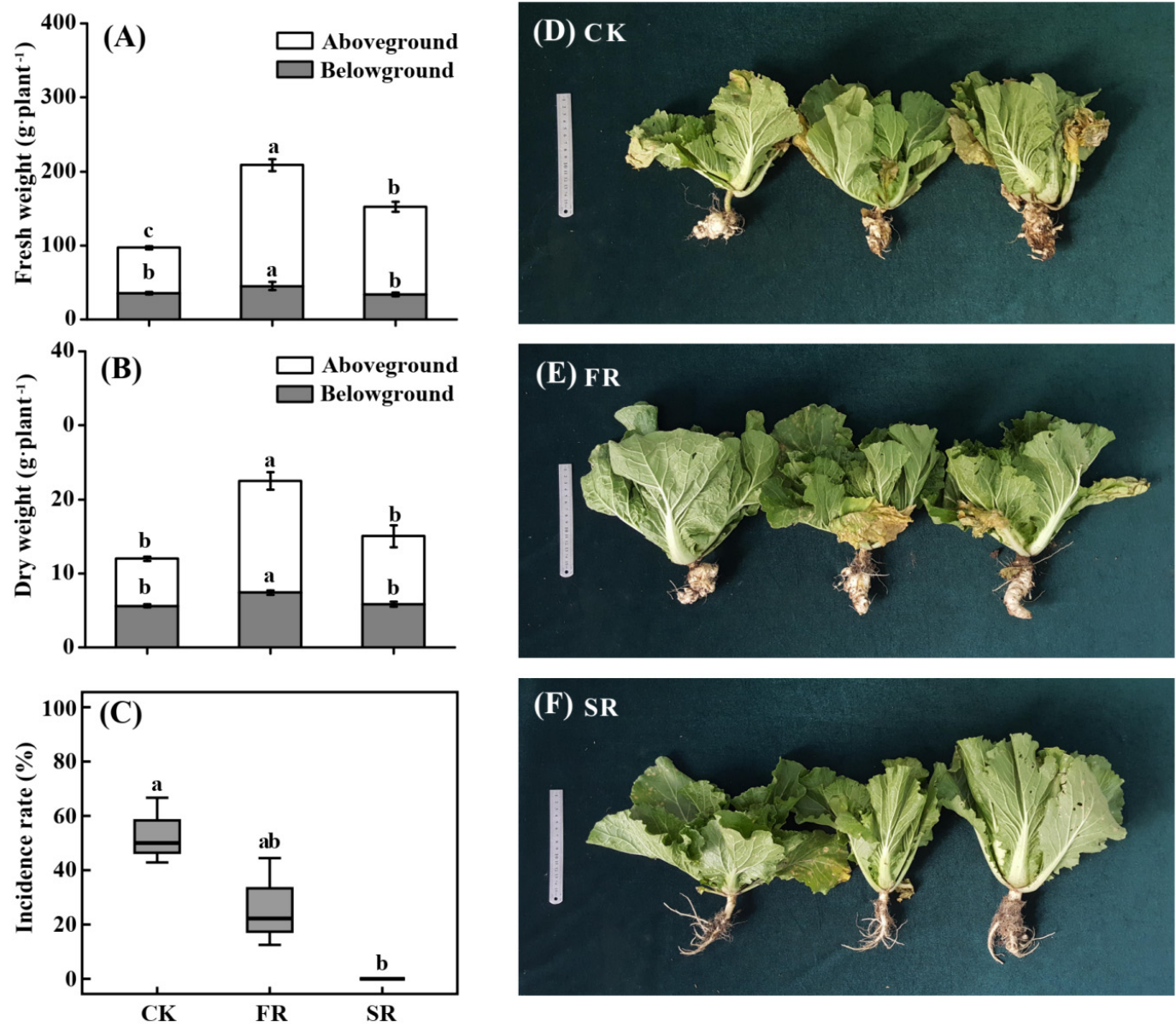

Figure 1. Plant weight and clubroot incidence rate in response to straw application. (A) Fresh weight. (B) dry weight, (C) incidence rate of clubroot and (D-F) Chinese cabbage plant after harvest. CK, no straw application; FR, one-year straw application; SR, two-year straw application. Error bars indicate the standard error, and different letters indicate significant differences at the 0.05 level (Tukey's HSD test). 
Studies of Fusarium wilt and root knot nematodes showed that the straw addition or intercropping with graminaceous crops has positive effects on suppression of soil-borne diseases [22,36]. We obtained similar results, in which the addition of rice straw decreased the incidence of clubroot and promoted plant growth of Chinese cabbage. Effective disease control is often manifested in delayed infection or a decrease in pathogen density [37]. Similarly, we found that CK resulted in swollen roots 40 days after sowing, while FR indicated symptoms after 50 days of sowing. Besides the control of disease symptoms, the abundance of survived spores in the soil was studied using quantitative PCR. Interestingly, we found that the abundance of resting spores was higher in SR treatment as compared to rest of the treatments (Supplementary Figure S1). This could be because the addition of rice straw during both years could have reduced the activity and pathogenicity of the pathogens, which should be examined in a long-term experiment in the future.

\subsection{The Soil Chemical Properties' Response to the Addition of Rice Straw}

The chemical properties of soil are directly related to the occurrence of soil-borne diseases [38]. The main soil chemical properties were determined in different periods and mean values (total) for each period (Figure 2). Compared to CK and FR, the SR treatment significantly increased SOM content at 20 days and total $(p<0.05)$. RMA analysis revealed that SOM contents were significantly altered in different treatments, at different periods and in combined action of treatment and period (interaction). Rice straw addition has a priming effect on SOM for a long period of time due to its slow decomposition rate under field conditions [39]. Our results suggested that the rice straw application increased SOM in the early periods, but this was not sustained in the later periods, which might be because the SOM contents are related to the decomposition rate of residues which vary with the time period.

Soil nutrients participate in many physiological processes, such as photosynthesis, water relationships, enzyme activation and assimilate transport, consequently impacting crop growth and yield [40]. After 60 days, the soil AP in SR was significantly higher than that of CK and FR $(p<0.05)$. RMA analysis showed that the soil AP was significantly changed in the different treatments and at different periods, but no significant change was observed in interaction $(p<0.05)$. Compared to CK and FR, the SR treatment increased AK at 10, 20 and 40 days. Compared to FR, the SR treatment increased AK at 20, 40 and 60 days $(p<0.05)$. RMA analysis showed that the soil AK was significantly changed in different treatments, at different periods and interaction $(p<0.05)$. Crop straw removal is a routine operation in intensive agricultural production, resulting in a rapid decline in soil nutrients and destroying the ecological sustainability [41]. The addition of straw may increase soil nitrogen fixation and mineralization in the short term, leading to a decrease in nitrogen deficiency and production [42]. In this study, rice straw addition had no obvious effect on the soil AN.

Compared to CK and FR, the SR treatment increased the soil $\mathrm{pH}$ at 10, 20 and 40 days. Compared to CK, the SR significantly increased the soil $\mathrm{pH}$ at 20 and 40 days $(p<0.05)$. RMA analysis showed that the soil $\mathrm{pH}$ was significantly altered in different treatments and at different periods $(p<0.05)$. Compared to CK and FR, the SR treatment increased the soil EC at 10 and 60 days. Compared to FR, the SR treatment increased the soil EC at 10, 20 and 60 days. RMA analysis showed that the soil EC was significantly changed in the different treatments, at different periods and interaction $(p<0.05)$. In soil, the dynamics of carbon and nitrogen affect $\mathrm{pH}$ and EC [43]. The minerals in rice straw compost may have caused the increase of EC [44]. A close relationship between $\mathrm{pH}$ and clubroot severity has been reported previously [45]. Research has also found that the application of Ca-rich organic matter controls clubroot occurrence due to the increase in soil pH [46]. Soil pH is the important indicator for soil degradation, as it can drive the subsurface microbial community structure and is correlated with the relative abundance of some bacteria [47]. However, the scientific and rational application of straw is encouraging for increasing soil nutrient levels and improving soil properties [48]. 

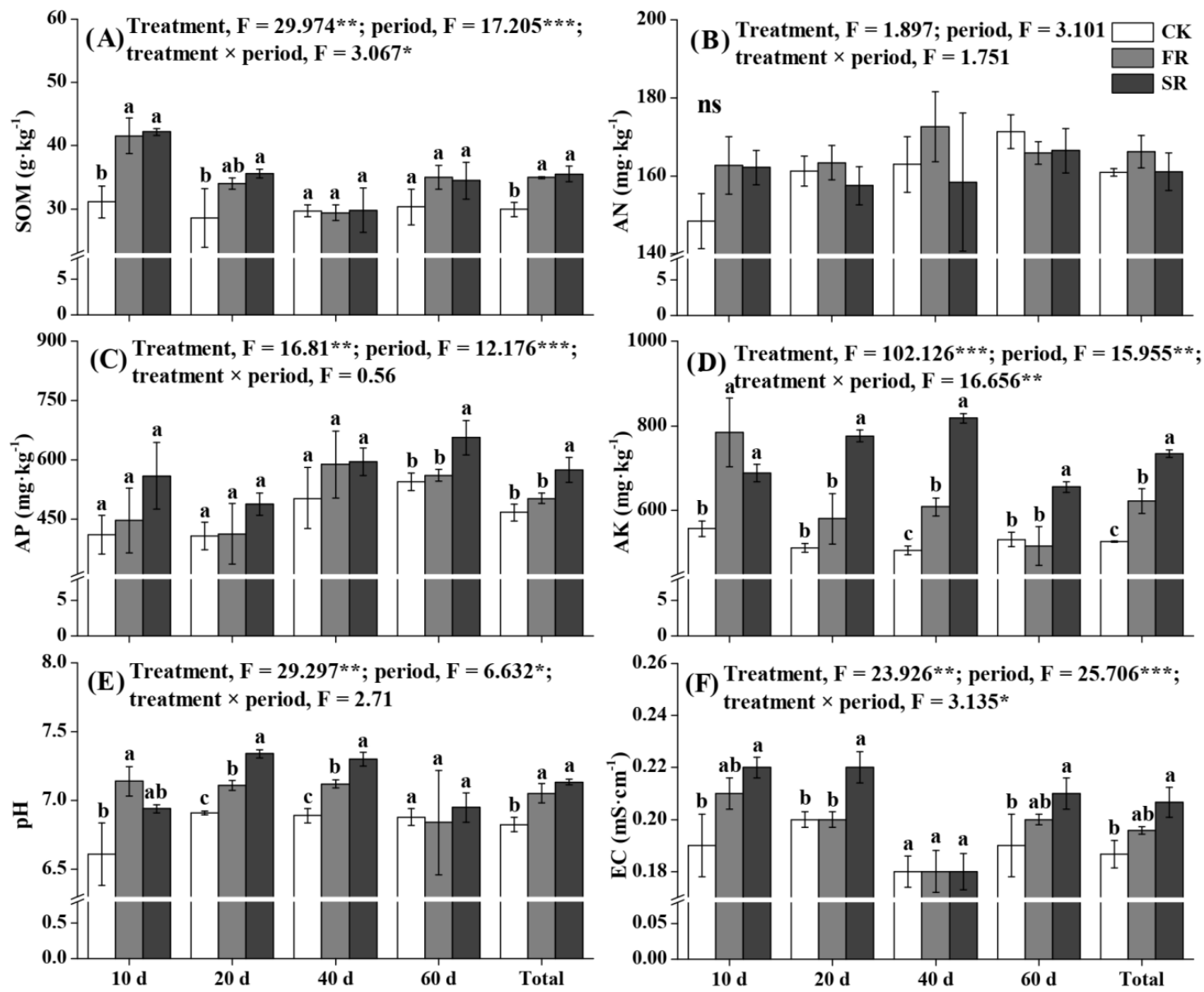

Figure 2. Soil chemical properties' response to straw application. (A) soil organic matter (SOM), (B) alkaline hydrolytic nitrogen (AN), (C) available phosphorus (AP), (D) available potassium (AK), (E) pH and (F) electrical conductivity (EC). CK, no straw application; FR, one-year straw application; SR, two-year straw application. Labels of the abscissa axis indicate the survey time (days after sowing), and total indicates the mean value for each period. Error bars indicate the standard error, ns indicates no significant differences between treatments and different letters indicate significant differences at the 0.05 level (Tukey's HSD test). The text in the figure represents the effects of the treatment and period based on the repeated-measures analysis of variance (ANOVA). ${ }^{*} p<0.05,{ }^{* *} p<0.01$ and ${ }^{* * *} p<0.001$.

\subsection{Modulation of Bacterial Community Diversity in Soils}

Across all soil samples, the Illumina MiSeq sequencing generated 7,962,387 optimized bacterial sequences. The effect of the addition of rice straw on the alpha diversity index is shown in Figure 3. The Good's coverage, which reflects the captured diversity, ranged from 0.985 to 0.995 for all samples. Compared to CK, the FR treatment significantly decreased the Shannon and Simpson indices at 10 and 60 days $(p<0.05)$. Compared to FR, the SR treatment significantly increased the Shannon and Simpson indices at 10 and 20 days $(p<0.05)$. Compared to CK and FR, the SR treatment decreased the Chao1 and ACE indices at all periods. Compared to FR, the SR treatment increased the Chao1 and ACE indices at 10 and 20 days but decreased that at 40 and 60 days. Similar results were found in number of OTUs analysis. The RMA analysis indicated that the treatments and time periods have significant effects on alpha diversity indices, while all the Shannon and Simpson indices were significantly influenced by interaction $(p<0.05)$.

In the analysis of alpha diversity indices, the richness and diversity of the bacterial community decreased after the application of rice straw, along with plant growth promotion and disease reduction. With rice straw and biochar application, the soil bacteria, actinomycetes and fungi work together to alleviate the acidification of continuously cropped soil [49]. The negative effect was found on bacterial diversity after the long-term application 
of fertilizers, which was alleviated by straw amendment [50]. Moreover, the structure and relative abundance of the bacterial community was changed with different expressions between the early and late periods in FR and SR. This may be linked to straw decomposition, because the straw used in this study had no carbonization or other forms of pretreatment.
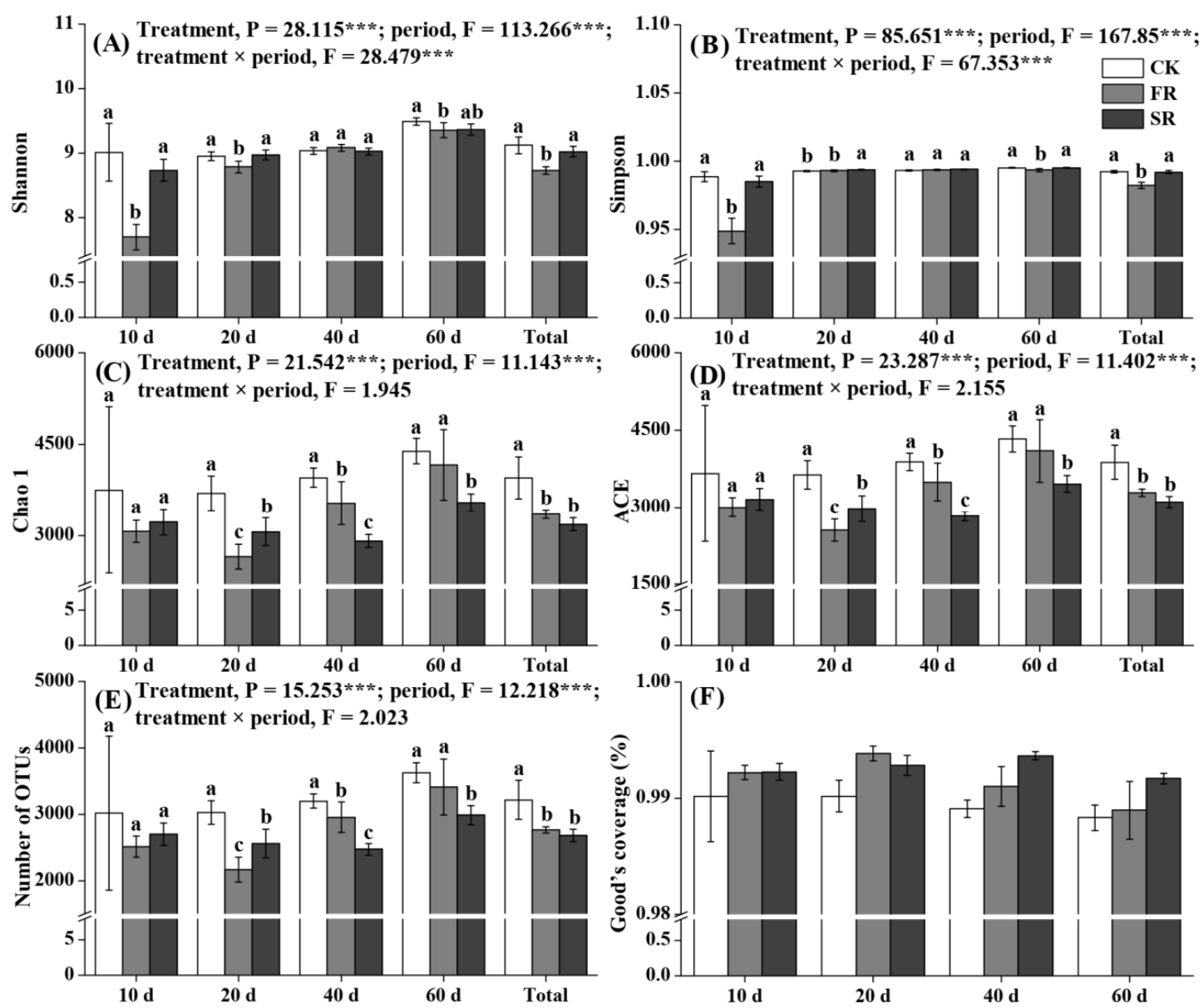

Figure 3. Alpha diversity based on Illumina MiSeq sequencing analysis of the soil bacteria in response to rice straw application. (A) Shannon, (B) Simpson, (C) Chao 1, (D) ACE, (E) Number of OTUs and (F) Good's coverage. CK, no straw application; FR, one-year straw application; SR, two-year straw application. Labels of the abscissa axis indicate the survey time (day after sowing), and total indicates the mean value for each period. Error bars indicate the standard error and different letters indicate significant differences at the 0.05 level (Tukey's HSD test). The text in the figure represents the effects of the treatment and period based on the repeated-measures ANOVA. ${ }^{* * *} p<0.001$.

For beta diversity, PCoA analysis revealed that the samples clustered tightly together within groups, while dispersed between groups (analysis of similarity, $\mathrm{R}=0.9998, p=0.001$; analysis of adonis, $\mathrm{R}^{2}=0.6746, p=0.001$ ) (Figure 4 ). The PCoA of the soil bacteria explained $19.79 \%$ and $10.23 \%$ of the community composition variation by the first two axes, respectively. The result of PCoA shows the obvious difference between early (10 and 20 days) and late (40 and 60 days) stages, consistent with that of the alpha diversity indices. Regarding the clubroot incidence, no obvious symptoms appear in the early stage of pathogen infection, except the occurrence of root gall formation during the primary and secondary metabolism [51]. This special period may be the key period of pathogen infection, causing differences in the microbe between the early and late stages. Soilborne plant pathogens can be suppressed by microbe or antagonistic competition, and the predominance of some bacteria may reduce the infection process and severity of clubroot [52]. Sustainable agriculture has to balance soil microorganisms with the control soil-borne diseases, and organic amendment has a beneficial influence [53]. 


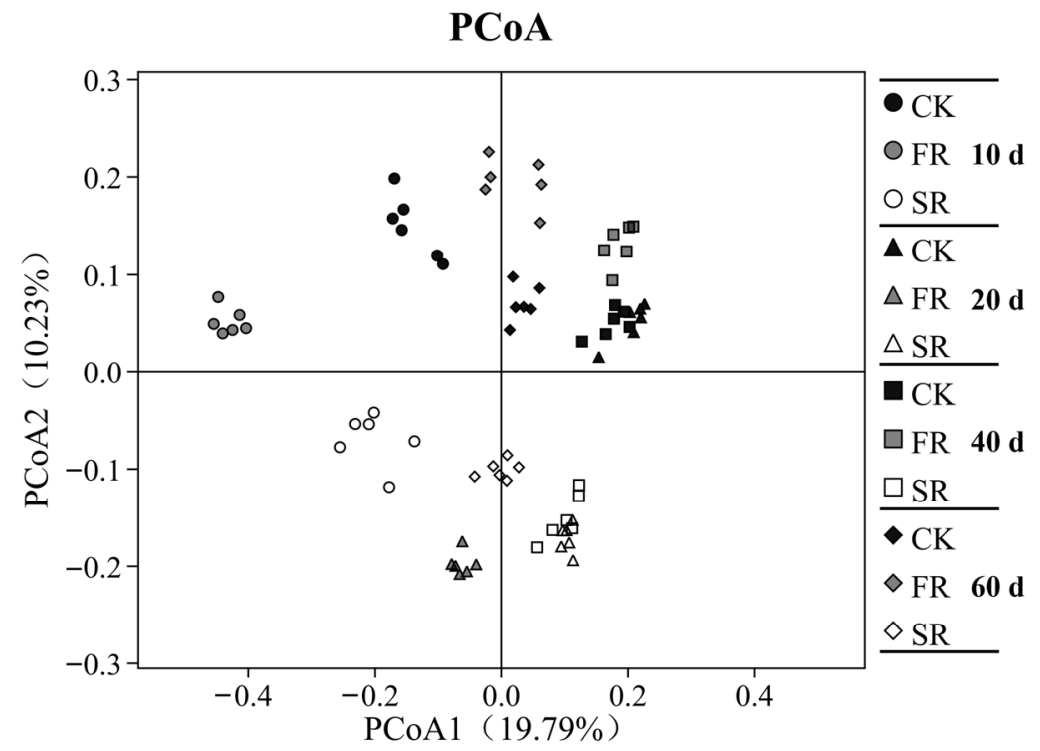

Figure 4. Principal coordinates analysis (PCoA) of soil bacterial response to straw application. CK, no straw application; FR, one-year straw application; SR, two-year straw application. Labels on the right indicate the survey time (day after sowing).

\subsection{Response of Bacterial Phyla Composition to the Addition of Rice Straw}

A total of 25 bacterial phyla were found across all the soil samples. The dominant bacteria phyla included Planctomycetes, Proteobacteria, Acidobacteria, Actinobacteria, Verrucomicrobia and Chloroflexi, combined accounting for $85.98 \%$ of the total OTUs. LEfSe analysis was used to assess the association between the bacterial phyla at different periods of time in the Chinese cabbage soil (average relative abundances $>0.1 \%$ ) (Figure 5).
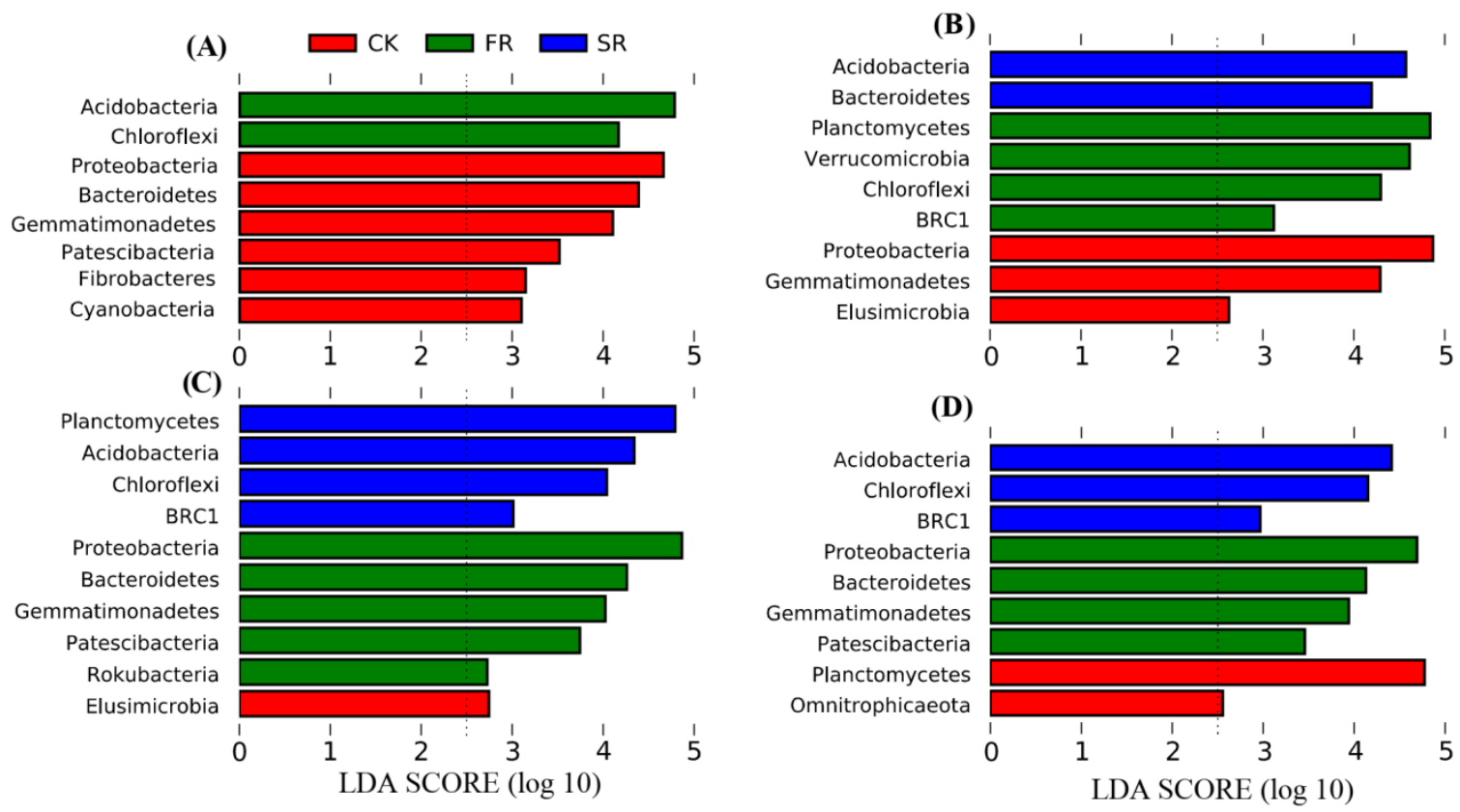

Figure 5. Linear discriminant analysis (LDA) histogram scores computed for the bacterial phyla response to straw application: (A) 10 days after sowing, (B) 20 days after sowing, (C) 40 days after sowing and (D) 60 days after sowing. CK, no straw application; FR, one-year straw application; SR, two-year straw application. The threshold employed for the logarithmic LDA score of the discriminative features was 2.0.

The histogram of LDA scores showed that Acidobacteria and Chloroflexi were more abundant with rice straw treatment (FR or SR) at all periods. Compared to CK, the SR 
treatment increased the relative abundances of Acidobacteria and Chloroflexi at all the periods (Figure 6). Acidobacteria is usually involved in the biogeochemical cycles, being numerically dominant and metabolically active in the soil [54]. Since the soil pH strongly influence species composition of Acidobacteria [55], the Pearson's correlation coefficient was used to analyze the correlation between the dominant bacterial phyla and the soil parameters (Supplementary Table S2). Our result showed that the $\mathrm{pH}$ had a positive correlation with Acidobacteria and Chloroflexi $(p<0.05)$. The Chloroflexi is considered as an important factor in the disease suppression of Fusarium wilt (a soil-borne disease) [22].
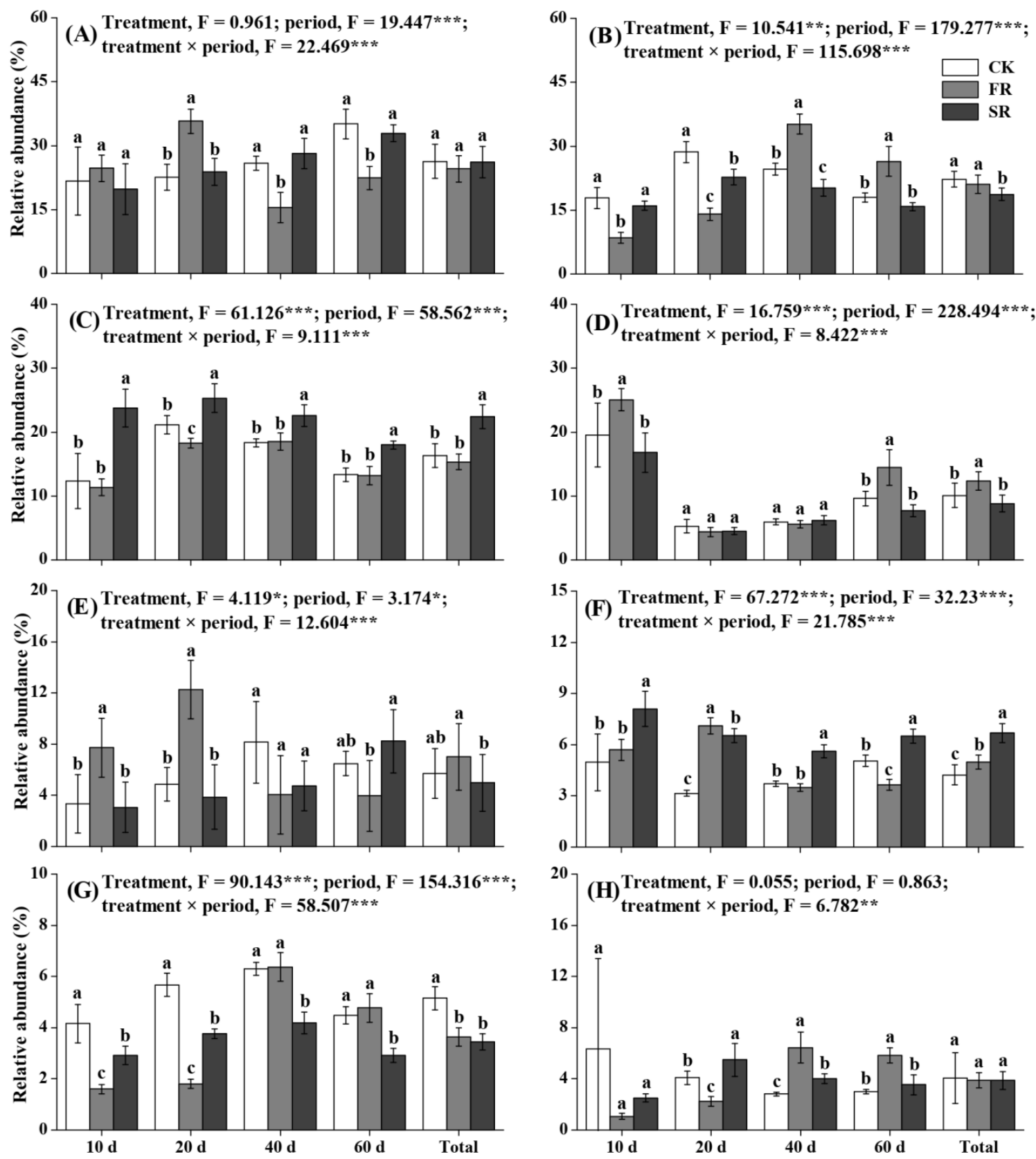

Figure 6. Relative abundances ( $>3 \%$ ) of the selected bacterial phyla response to straw application: (A) Planctomycetes, (B) Proteobacteria, (C) Acidobacteria, (D) Actinobacteria, (E) Verrucomicrobia, (F) Chloroflexi, (G) Gemmatimonadetes and (H) Bacteroidetes. CK, no straw application; FR, one-year straw application; SR, two-year straw application. Labels of the abscissa axis indicate the survey time (day after sowing), and total indicates the mean value for each period. Error bars indicate the standard error, and different letters indicate significant differences at the 0.05 level (Tukey's HSD test). The text in the figure represents the effects of the treatment and period based on the repeated-measures ANOVA. ${ }^{*} p<0.05,{ }^{* *} p<0.01$ and $* * * p<0.001$. 
The Bacteroidetes and $B R C 1$ were also more abundant in the rice straw treatments, except for at the period of 10 days. The relative abundance of Bacteroidetes was higher with SR than CK at 40 and 60 days. BRC1, a dominant member of microbial communities, was detected in environments in organic matter, and also has a specialized metabolism like organotrophic bacteria [56]. Bacteroidetes secrete carbohydrate-active enzymes to promote cell surface foraging of nutrients [57]; however, Bacteroidetes had a negative correlation with SOM $(p<0.05)$ in this study.

Meanwhile, Gemmatimonadetes and Proteobacteria were more abundant in CK at 10 and 20 days, and more abundant in FR at 40 and 60 days. The relative abundance of Proteobacteria with FR was lower than that of CK at 10 and 20 days, but the opposite pattern was observed at 40 and 60 days. The relative abundance of Gemmatimonadetes with FR was lower than that of CK at 10 and 20 days $(p<0.05)$. However, the relative abundances of Gemmatimonadetes and Proteobacteria were lower at all periods in SR as compared to CK. This may be due to the seasonal variations in Gemmatimonadetes as the phylum adapt the low-moisture environment soils [58]. The soil parameters, including SOM, AK and EC, had negative correlation with Proteobacteria and Gemmatimonadetes $(p<0.05)$.

The most prominent phyla among soil bacteria in agricultural soils are Proteobacteria and Acidobacteria [55]. In addition to those, Planctomycetes, Actinobacteria and Verrucomicrobia were also detected as dominant phyla in our study. Compared to CK, the relative abundances of Planctomycetes and Verrucomicrobia were increased in FR at 10 and 20 days and decreased at 40 and 60 days. FR increased the relative abundance of Actinobacteria at 10 and 60 days compared to CK. Actinobacteria, Firmicutes and Bacteroidetes are known as hydrolytic organisms that act as organic matter degraders [59].

With straw residue applied to soil, the microbe participates in the decomposition of easily decomposable substances at the early stages [60]. Rate-limiting organic matter needs a long time to degrade, such as lignocellulose, cellulose and hemicellulose [61]. For example, Bacteroidetes and Proteobacteria are closely related to cellulose decomposition [62]. In our study, FR increased the relative abundance of Actinobacteria. Such an increase may activate phytosanitary resistance and may be related to the decomposition process of straw [63]. Planting soybean before oilseed rape significantly increased the population density of Sphingomonas that could inhibit P. brassicae [15]. However, there was no consistent influence after the application of rice straw in our study. As a valuable recycling strategy, the positive effect of residue amendment includes the selection of microbial populations, and the inconsistent results were shown in bacterial and fungal diversity $[64,65]$.

\subsection{Response of the Bacterial Genera Composition to the Addition of Rice Straw}

LEfSe analysis was further used to assess the association of the bacterial genera in the Chinese cabbage soil (average relative abundances > 0.1\%) (Supplementary Figure S2). The histogram of LDA scores showed that CK resulted in more abundant genera than the straw application treatments at the first two periods, while FR resulted in more abundant genera at the last two periods. Of the bacterial genera in all periods, Iamia was more abundant in CK, Chitinophaga and Pantoea were more abundant in FR, and RB41 and Aridibacter were more abundant in SR. In the LEfSe analysis, the selected bacterial genera of network analysis showed more abundance in the straw application treatments, except Sphingomonas in CK at 10 and 20 days. The abundance of Gemmata was enriched by FR at 20 days and SR at 40 and 60 days. FR enriched the abundance of Steroidobacter at 40 and 60 days.

With the obtained bacterial genera data, network analysis was used for further investigation (Supplementary Figure S3). Compared to the other bacterial genera, Gemmata had the highest relative abundance and more compact connectivity. Moreover, the relative abundance of key genera involved in bacterial networking was differentially affected by the rice straw amendment (Supplementary Figure S4). The results of Pearson's correlation coefficient for key genera are presented in Supplementary Table S3.

Compared to CK, the FR treatment increased the relative abundances of Gemmata, Pirellula, Candidatus Udaeobacter and Rhodopirellula at 10 and 20 days, but decreased those at 
40 and 60 days. Meanwhile, SOM was positively correlated with these bacterial genera. The opposite trend was shown for the relative abundances of Sphingomonas, Steroidobacter, Thermomonas and Terrimonas in FR treatment. Compared to CK, the relative abundances of Gemmata, Pirellula and Rhodopirellula were increased in SR, while the relative abundances of Sphingomonas, Candidatus Udaeobacter, Thermomonas and Terrimonas were decreased. In addition, the soil parameters were positively correlated with Gemmata, Pirellula and Rhodopirellula, but negatively correlated with the rest of the key bacterial genera. The $\mathrm{pH}$ was significantly negatively associated with Terrimonas, and SOM, AK and EC were negatively related with Terrimonas $(p<0.05)$.

The changes in the bacterial community in different stages should be paid more attention for evaluating fertilization, particularly distinguishing between early and later stages [66]. The relative abundance of bacteria was different at early periods (10 and 20 days after sowing) and the late periods (40 and 60 days after sowing). This might be directly related to the variation in decomposition rate of added rice residues. The application of different crop residues has been shown to change the soil environment at the different phases of decomposition $[67,68]$. Besides straw decomposition, disease progress should also be considered, thus further studies are necessary to dynamically explore and monitor the soil environment during clubroot disease.

\section{Conclusions}

This study concludes that the rice straw application decreased the alpha diversity and altered the composition of bacterial community in the Chinese cabbage soil. In addition, straw application increased the $\mathrm{SOM}, \mathrm{pH}, \mathrm{EC}, \mathrm{AP}$ and $\mathrm{AK}$. The relative abundances of Acidobacteria and Chloroflexi increased after the application of rice straw, which were associated with soil AK and $\mathrm{pH}$. Repeated application of straw was conducive to the stability of the bacterial community composition. Moreover, the straw application inhibited the severity of clubroot in the field - particularly the repeated application-and promoted the plant growth of the Chinese cabbage- but one-year application. However, quantitative PCR confirmed that the abundance of resting spores was increased in straw treatment, which provided the new knowledge that the two-year repeated application of crop residues might not be enough for complete inhibition of P. brassicae infection in Chinese cabbage. Although, this study stressed the viewpoint that gramineous crop straw application to the vegetable field is a promising strategy for enhancing agricultural sustainability. However, further field studies are needed to evaluate the long-term effects of crop straw on soil-borne pathogenic microbes as well as overall soil microbial immunities and physicochemical properties.

Supplementary Materials: The following are available online at https:/ /www.mdpi.com/2077-047 2/11/2/108/s1: Figure S1: Abundance of Plasmodiophora brassicae in response to straw application; Figure S2: Linear discriminant analysis (LDA) histogram scores computed for the bacterial genera response to straw application; Figure S3: Network plots of the bacterial community at the genus level; Figure S4: Relative abundance of the selected bacterial genera response to straw application; Table S1: Basic soil chemical properties of the cultivated soil in the second year; Table S2: Pearson's correlation coefficients between the bacterial phyla and chemical properties in the soils; Table S3: Pearson's correlation coefficients between the bacterial genera and chemical properties in the soils.

Author Contributions: All authors declare that everyone contributed adequately to the experimental procedures and writing of the manuscript. Data curation, Z.H.; funding acquisition, F.W. and K.P.; investigation, Z.H. and C.D.; methodology, Z.H. and C.D.; project administration, F.W. and K.P.; writing-original draft, Z.H.; writing—review and editing, Z.H., D.G. and M.K.uR. All authors have read and agreed to the published version of the manuscript.

Funding: This research was funded by the China Agricultural Research System (grant number CARS23-B-10) and the Collaborative Innovation Extension System of Modern Agricultural (Vegetables) Industrial Technology in Heilongjiang Province (grant number HNWJZTX201701).

Institutional Review Board Statement: Not applicable. 
Informed Consent Statement: Not applicable.

Data Availability Statement: Data are available by contacting the authors.

Acknowledgments: The authors thank Pen Lu, Yiping Zhang, and Xuehan Wang from Northeast Agricultural University for the field operation, experimental measurements, data analysis, and valuable comments regarding the improvement of the manuscript. Thanks are also given to the Cabbage Research Group of Northeast Agricultural University (Harbin, China) for providing test materials of Chinese cabbage seeds for this experimental research.

Conflicts of Interest: The authors declare no conflict of interest.

\section{References}

1. Hwang, S.F.; Strelkov, S.E.; Feng, J.; Gossen, B.D.; Howard, R.J. Plasmodiophora brassicae: A review of an emerging pathogen of the Canadian canola (Brassica napus) crop. Mol. Plant Pathol. 2012, 13, 105-113. [CrossRef] [PubMed]

2. Chai, A.L.; Xie, X.W.; Shi, Y.X.; Li, B.J. Research status of clubroot (Plasmodiophora brassicae) on cruciferous crops in China. Can. J. Plant Pathol. 2014, 36, 142-153. [CrossRef]

3. Donald, C.; Porter, I. Integrated Control of Clubroot. J. Plant Growth Regul. 2009, 28, 289-303. [CrossRef]

4. Sharma, K.; Gossen, B.; McDonald, M.R. Effect of temperature on primary infection by Plasmodiophora brassicae. Plant Pathol. 2011, 60, 830-838. [CrossRef]

5. Samuel, G.; Garrett, S.D. The infected root-hair count for estimating the activity of Plasmodiophora brassicae Woron. in the soil. Ann. Appl. Biol. 2010, 32, 96-101. [CrossRef]

6. Dixon, G.R. The Occurrence and Economic Impact of Plasmodiophora brassicae and Clubroot Disease. J. Plant Growth Regul. 2009, 28, 194-202. [CrossRef]

7. Ahmed, H.U.; Hwang, S.F.; Strelkov, S.E.; Gossen, B.D.; Peng, G.; Howard, R.J.; Turnbull, G.D. Assessment of bait crops to reduce inoculum of clubroot (Plasmodiophora brassicae) of canola. Can. J. Plant Sci. 2011, 91, 545-551. [CrossRef]

8. Hwang, S.F.; Ahmed, H.U.; Zhou, Q.; Turnbull, G.D.; Strelkov, S.E.; Gossen, B.D.; Peng, G. Effect of host and non-host crops on Plasmodiophora brassicae resting spore concentrations and clubroot of canola. Plant Pathol. 2015, 64, 1198-1206. [CrossRef]

9. Murakami, H.; Tsushima, S.; Shishido, Y. Soil suppressiveness to clubroot disease of Chinese cabbage caused by Plasmodiophora brassicae. Soil Biol. Biochem. 2000, 32, 1637-1642. [CrossRef]

10. Ney, L.; Franklin, D.; Mahmud, K.; Cabrera, M.; Fatzinger, B. Rebuilding Soil Ecosystems for Improved Productivity in Biosolarized Soils. Int. J. Agron. 2019, 2019, 1-10. [CrossRef]

11. Hwang, S.F.; Howard, R.J.; Strelkov, S.E.; Gossen, B.D.; Peng, G. Management of clubroot (Plasmodiophora brassicae) on canola (Brassica napus) in western Canada. Can. J. Plant Pathol. 2014, 36, 49-65. [CrossRef]

12. Narisawa, K.; Tokumasu, S.; Hashiba, T. Suppression of clubroot formation in Chinese cabbage by the root endophytic fungus, Heteroconium chaetospira. Plant Pathol. 2010, 47, 206-210. [CrossRef]

13. Mahmud, K.; Franklin, D.; Ney, L.; Cabrera, M.; Habteselassie, M.; Hancock, D.; Newcomer, Q.; Subedi, A.; Dahal, S. Improving inorganic nitrogen in soil and nutrient density of edamame bean in three consecutive summers by utilizing a locally sourced bio-inocula. Org. Agric. 2021. [CrossRef]

14. Peng, G.; Lahlali, R.; Hwang, S.-F.; Pageau, D.; Hynes, R.K.; McDonald, M.R.; Gossen, B.D.; Strelkov, S.E. Crop rotation, cultivar resistance, and fungicides/biofungicides for managing clubroot (Plasmodiophora brassicae) on canola. Can. J. Plant Pathol. 2014, 36, 99-112. [CrossRef]

15. Yang, X.X.; Huang, X.Q.; Wen-Xian, W.U.; Xiang, Y.J.; Liu, Y. Effects of different rotation patterns on the occurrence of clubroot disease and diversity of rhizosphere microbes. J. Integr. Agric. 2020, 19, 2265-2273. [CrossRef]

16. Howard, R.J.; Strelkov, S.E.; Harding, M.W. Clubroot of cruciferous crops-New perspectives on an old disease. Can. J. Plant Pathol. 2010, 32, 43-57. [CrossRef]

17. Rifai, S.W.; Markewitz, D.; Borders, B. Twenty years of intensive fertilization and competing vegetation suppression in loblolly pine plantations: Impacts on soil C, N, and microbial biomass. Soil Biol. Biochem. 2010, 42, 713-723. [CrossRef]

18. Chen, S.C.; Zhou, X.G.; Yu, H.J.; Wu, F.Z. Root exudates of potato onion are involved in the suppression of clubroot in a Chinese cabbage-potato onion-Chinese cabbage crop rotation. Eur. J. Plant Pathol. 2018, 150, 765-777. [CrossRef]

19. Liu, C.; Yang, Z.; He, P.; Munir, S.; Wu, Y.; Ho, H.; He, Y. Deciphering the bacterial and fungal communities in clubroot-affected cabbage rhizosphere treated with Bacillus Subtilis XF-1. Agric. Ecosyst. Environ. 2018, 256, 12-22. [CrossRef]

20. Walkley, A.; Black, I.A. An Examination of the Degtjareff Method for Determining Soil Organic Matter, and A Proposed Modification of the Chromic Acid Titration Method. Soil Sci. 1934, 37, 29-38. [CrossRef]

21. Li, N.; Gao, D.; Zhou, X.; Chen, S.; Wu, F. Intercropping with Potato-Onion Enhanced the Soil Microbial Diversity of Tomato. Microorganisms 2020, 8, 834. [CrossRef] [PubMed]

22. Tang, L.; Xia, Y.; Fan, C.; Kou, J.; Wu, F.; Li, W.; Pan, K. Control of Fusarium wilt by wheat straw is associated with microbial network changes in watermelon rhizosphere. Sci. Rep. 2020, 10, 12736. [CrossRef] [PubMed] 
23. Sundelin, T.; Christensen, C.B.; Larsen, J.; Mller, K.; Lübeck, M.; Bdker, L.; Jensen, B. In Planta Quantification of Plasmodiophora brassicae Using Signature Fatty Acids and Real-Time PCR. Plant Dis. Int. J. Appl. Plant Pathol. 2010, 94, 432-438. [CrossRef] [PubMed]

24. Crowther, T.W.; Maynard, D.S.; Leff, J.W.; Oldfield, E.E.; Mcculley, R.L.; Fierer, N.; Bradford, M.A. Predicting the responsiveness of soil biodiversity to deforestation: A cross-biome study. Glob. Change Biol. 2014, 20, 2983-2994. [CrossRef]

25. Chen, S.; Zhou, Y.; Chen, Y.; Gu, J. Fastp: An ultra-fast all-in-one FASTQ preprocessor. Bioinformatics 2018, 34, 884-890. [CrossRef] [PubMed]

26. Magoc, T.; Salzberg, S.L. FLASH: Fast length adjustment of short reads to improve genome assemblies. Bioinformatics 2011, 27, 2957-2963. [CrossRef]

27. Caporaso, J.G.; Kuczynski, J.; Stombaugh, J.; Bittinger, K.; Bushman, F.D.; Costello, E.K.; Fierer, N.; Pena, A.G.; Goodrich, J.K.; Gordon, J.I.; et al. QIIME allows analysis of high-throughput community sequencing data. Nat. Methods 2010, 7, 335-336. [CrossRef]

28. Bokulich, N.A.; Subramanian, S.; Faith, J.J.; Gevers, D.; Gordon, J.I.; Knight, R.; Mills, D.A.; Caporaso, J.G. Quality-filtering vastly improves diversity estimates from Illumina amplicon sequencing. Nat. Methods 2013, 10, 57-59. [CrossRef]

29. Edgar, R.C.; Haas, B.J.; Clemente, J.C.; Quince, C.; Knight, R. UCHIME improves sensitivity and speed of chimera detection. Bioinformatics 2011, 27, 2194-2200. [CrossRef]

30. Edgar, R.C. UPARSE: Highly accurate OTU sequences from microbial amplicon reads. Nat. Methods 2013, 10, 996-998. [CrossRef]

31. Wang, Q.; Garrity, G.M.; Tiedje, J.M.; Cole, J.R. Naive Bayesian classifier for rapid assignment of rRNA sequences into the new bacterial taxonomy. Appl. Environ. Microbiol. 2007, 73, 5261-5267. [CrossRef] [PubMed]

32. Pruesse, E.; Quast, C.; Knittel, K.; Fuchs, B.M.; Ludwig, W.; Peplies, J.; Gloeckner, F.O. SILVA: A comprehensive online resource for quality checked and aligned ribosomal RNA sequence data compatible with ARB. Nucleic Acids Res. 2007, 35, 7188-7196. [CrossRef] [PubMed]

33. Tang, L.; Nie, S.; Li, W.; Fan, C.; Wang, S.; Wu, F.; Pan, K. Wheat straw increases the defense response and resistance of watermelon monoculture to Fusarium wilt. BMC Plant Biol. 2019, 19, 551. [CrossRef] [PubMed]

34. Gong, Z.Y.; Fu, X.P.; Zhou, X.G.; Wu, F.Z.; Liu, S.W. Effects of plant residues on cucumber (Cucumis sativus L) growth, soil enzyme activities and microbial communities. Allelopath. J. 2016, 38, 147-157.

35. Zhou, X.; Wu, F. Changes in soil chemical characters and enzyme activities during continuous monocropping of cucumber (Cucumis sativus). Pak. J. Bot. 2015, 47, 691-697.

36. Zhang, Y.; Li, Z.L.; Wang, S.W.; Wu, F.Z.; Pan, K. Effects of crop straws on root knot nematodes and soil fungal community in continuous cropping of tomato. Allelopath. J. 2017, 42, 79-92. [CrossRef]

37. Hwang, S.F.; Ahmed, H.U.; Strelkov, S.E.; Gossen, B.D.; Turnbull, G.D.; Peng, G.; Howard, R.J. Seedling age and inoculum density affect clubroot severity and seed yield in canola. Can. J. Plant Sci. 2011, 91, 183-190. [CrossRef]

38. Yang, Y.; Wu, L.; Lin, Q.; Yuan, M.; Xu, D.; Yu, H.; Hu, Y.; Duan, J.; Li, X.; He, Z.; et al. Responses of the functional structure of soil microbial community to livestock grazing in the Tibetan alpine grassland. Glob. Change Biol. 2013, 19, 637-648. [CrossRef]

39. Ye, R.; Doane, T.A.; Morris, J.; Horwath, W.R. The effect of rice straw on the priming of soil organic matter and methane production in peat soils. Soil Biol. Biochem. 2015, 81, 98-107. [CrossRef]

40. Pettigrew, W.T. Potassium influences on yield and quality production for maize, wheat, soybean and cotton. Physiol. Plant. 2008, 133, 670-681. [CrossRef]

41. Kleinman, P.J.A.; Pimentel, D.; Bryant, R.B. The ecological sustainability of slash-and-burn agriculture. Agric. Ecosyst. Environ. 1995, 52, 235-249. [CrossRef]

42. Mourtzinis, S.; Gaska, J.; Diallo, T.; Lauer, J.G.; Conley, S. Legacy Effects of Three Management Practices on Corn, Soybean, and Wheat Yield. Agron. J. 2018, 110, 418-424. [CrossRef]

43. Dendooven, L.; Alcántara-Hernández, R.J.; Valenzuela-Encinas, C.; Luna-Guido, M.; Perez-Guevara, F.; Marsch, R. Dynamics of carbon and nitrogen in an extreme alkaline saline soil: A review. Soil Biol. Biochem. 2010, 42, 865-877. [CrossRef]

44. Cheng, W.; Padre, A.T.; Shiono, H.; Sato, C.; Nguyen-Sy, T.; Tawaraya, K.; Kumagai, K. Changes in the pH, EC, available P, SOC and TN stocks in a single rice paddy after long-term application of inorganic fertilizers and organic matters in a cold temperate region of Japan. J. Soils Sediments 2017, 17, 1834-1842. [CrossRef]

45. Wei, T.; Zhang, P.; Wang, K.; Ding, R.; Yang, B.; Nie, J.; Jia, Z.; Han, Q. Effects of Wheat Straw Incorporation on the Availability of Soil Nutrients and Enzyme Activities in Semiarid Areas. PLoS ONE 2015, 10, e0120994. [CrossRef]

46. Niwa, R.; Kumei, T.; Nomura, Y.; Yoshida, S.; Osaki, M.; Ezawa, T. Increase in soil pH due to Ca-rich organic matter application causes suppression of the clubroot disease of crucifers. Soil Biol. Biochem. 2007, 39, 778-785. [CrossRef]

47. Green, S.J.; Prakash, O.; Jasrotia, P.; Overholt, W.A.; Cardenas, E.; Hubbard, D.; Tiedje, J.M.; Watson, D.B.; Schadt, C.W.; Brooks, S.C. Denitrifying bacteria from the genus Rhodanobacter dominate bacterial communities in the highly contaminated subsurface of a nuclear legacy waste site. Appl. Environ. Microbiol. 2012, 78, 1039-1047. [CrossRef]

48. Su, Y.; Lv, J.L.; Yu, M.; Ma, Z.H.; Xi, H.; Kou, C.L.; He, Z.C.; Shen, A.L. Long-term decomposed straw return positively affects the soil microbial community. J. Appl. Microbiol. 2019, 128, 138-150. [CrossRef]

49. Zhang, Y.M.; Liu, Y.F.; Zhang, G.X.; Guo, X.O.; Sun, Z.P.; Li, T.L. The Effects of Rice Straw and Biochar Applications on the Microbial Community in a Soil with a History of Continuous Tomato Planting History. Agronomy Basel 2018, 8, 65. [CrossRef] 
50. Ramirez, K.S.; Lauber, C.L.; Knight, R.; Bradford, M.A.; Fierer, N. Consistent effects of nitrogen fertilization on soil bacterial communities in contrasting systems. Ecology 2010, 91, 3463-3470. [CrossRef]

51. Ludwig-Mueller, J.; Prinsen, E.; Rolfe, S.A.; Scholes, J.D. Metabolism and Plant Hormone Action During Clubroot Disease. J. Plant Growth Regul. 2009, 28, 229-244. [CrossRef]

52. Saraiva, A.L.d.R.F.; Bhering, A.d.S.; do Carmo, M.G.F.; Andreote, F.D.; Dias, A.C.F.; Coelho, I.d.S. Bacterial composition in brassica-cultivated soils with low and high severity of clubroot. J. Phytopathol. 2020, 168, 613-619. [CrossRef]

53. Vida, C.; de Vicente, A.; Cazorla, F.M. The role of organic amendments to soil for crop protection: Induction of suppression of soilborne pathogens. Ann. Appl. Biol. 2020, 176, 1-15. [CrossRef]

54. Lee, S.-H.; Ka, J.-O.; Cho, J.-C. Members of the phylum Acidobacteria are dominant and metabolically active in rhizosphere soil. FEMS Microbiol. Lett. 2008, 285, 263-269. [CrossRef] [PubMed]

55. Miyashita, N.T. Contrasting soil bacterial community structure between the phyla Acidobacteria and Proteobacteria in tropical Southeast Asian and temperate Japanese forests. Genes Genet. Syst. 2015, 90, 61-77. [CrossRef] [PubMed]

56. Kadnikov, V.V.; Mardanov, A.V.; Beletsky, A.V.; Rakitin, A.L.; Frank, Y.A.; Karnachuk, O.V.; Ravin, N.V. Phylogeny and physiology of candidate phylum BRC1 inferred from the first complete metagenome-assembled genome obtained from deep subsurface aquifer. Syst. Appl. Microbiol. 2019, 42, 67-76. [CrossRef]

57. Larsbrink, J.; McKee, L.S. Bacteroidetes bacteria in the soil: Glycan acquisition, enzyme secretion, and gliding motility. In Advances in Applied Microbiology; Gadd, G.M., Sariaslani, S., Eds.; Academic Press: Cambridge, MA, USA, 2020; Chapter 2, Volume 110, pp. 63-98.

58. DeBruyn, J.M.; Nixon, L.T.; Fawaz, M.N.; Johnson, A.M.; Radosevich, M. Global Biogeography and Quantitative Seasonal Dynamics of Gemmatimonadetes in Soil. Appl. Environ. Microbiol. 2011, 77, 6295-6300. [CrossRef]

59. Naumoff, D.G.; Dedysh, S.N. Bacteria from Poorly Studied Phyla as a Potential Source of New Enzymes: $\beta$-Galactosidases from Planctomycetes and Verrucomicrobia. Microbiology 2018, 87, 796-805. [CrossRef]

60. Jifu, L.; Jianwei, L.; Xiaokun, L.; Tao, R.; Rihuan, C.; Li, Z. Dynamics of Potassium Release and Adsorption on Rice Straw Residue. PLoS ONE 2014, 9, e90440. [CrossRef]

61. Reinhold-Hurek, B.; Buenger, W.; Burbano, C.S.; Sabale, M.; Hurek, T. Roots Shaping Their Microbiome: Global Hotspots for Microbial Activity. Annu. Rev. Phytopathol. 2015, 53, 403-424. [CrossRef]

62. Espana, M.; Rasche, F.; Kandeler, E.; Brune, T.; Rodriguez, B.; Bending, G.D.; Cadisch, G. Identification of active bacteria involved in decomposition of complex maize and soybean residues in a tropical Vertisol using N-15-DNA stable isotope probing. Pedobiologia 2011, 54, 187-193. [CrossRef]

63. Wang, Y.; Chang, S.X.; Fang, S.; Tian, Y. Contrasting decomposition rates and nutrient release patterns in mixed vs singular species litter in agroforestry systems. J. Soils Sediments 2014, 14, 1071-1081. [CrossRef]

64. Tang, H.M.; Xiao, X.P.; Tang, W.G.; Lin, Y.C.; Wang, K.; Yang, G.L.; Hauke, S. Effects of Winter Cover Crops Residue Returning on Soil Enzyme Activities and Soil Microbial Community in Double-Cropping Rice Fields. PLoS ONE 2014, 9, e100443. [CrossRef]

65. Li, J.; Philp, J.; Li, J.; Wei, Y.; Wang, Y. Trichoderma harzianum Inoculation Reduces the Incidence of Clubroot Disease in Chinese Cabbage by Regulating the Rhizosphere Microbial Community. Microorganisms 2020, 8, 1325. [CrossRef] [PubMed]

66. Yu, C.; Hu, X.M.; Deng, W.; Li, Y.; Xiong, C.; Ye, H.; Han, G.M.; Li, X. Changes in soil microbial community structure and functional diversity in the rhizosphere surrounding mulberry subjected to long-term fertilization. Appl. Soil Ecol. 2015, 86, 30-40. [CrossRef]

67. Grünwald, N.J.; Hu, S.; Bruggen, A.H.C.V. Short-term cover crop decomposition in organic and conventional soils: Characterization of soil C, N, microbial and plant pathogen dynamics. Eur. J. Plant Pathol. 2000, 106, 37-50. [CrossRef]

68. Liu, J.; Meng, Z.; Liu, X.; Zhang, X.H. Microbial assembly, interaction, functioning, activity and diversification: A review derived from community compositional data. Mar. Life Sci. Technol. 2019, 1, 112-128. [CrossRef] 